\title{
Celiac Disease Diagnosed in an Older Adult Patient with a Complex Neuropsychiatric Involvement: A Case Report and Review of the Literature
}

\author{
Emma Falato ${ }^{1}$, Fioravante Capone ${ }^{1}$, Federico Ranieri ${ }^{2}{ }^{\oplus}$, Lucia Florio ${ }^{3}$, Marzia Corbetto ${ }^{4}$, \\ Chiara Taffon ${ }^{5}$, Cinzia Niolu ${ }^{6}$, Giorgio Di Lorenzo ${ }^{6}\left(\mathbb{D}\right.$ and Vincenzo Di Lazzaro ${ }^{1, *(1)}$ \\ 1 Unit of Neurology, Neurophysiology, Neurobiology, Department of Medicine, \\ Università Campus Bio-Medico di Roma, via Álvaro del Portillo 200, 00128 Rome, Italy; \\ e.falato@unicampus.it (E.F.); f.capone@unicampus.it (F.C.) \\ 2 Department of Neuroscience, Biomedicine and Movement Sciences, University of Verona, \\ 37134 Verona, Italy; federico.ranieri@univr.it \\ 3 Unit of Neurology, IRCCS Casa Sollievo della Sofferenza, San Giovanni Rotondo, 71013 Foggia, Italy; \\ luciaflorio81@gmail.com \\ 4 Department of Neurology, Santa Maria Goretti Hospital, 04100 Latina, Italy; m.corbetto@ausl.latina.it \\ 5 Unit of Pathology, Università Campus Bio-Medico di Roma, via Álvaro del Portillo 200, 00128 Rome, Italy; \\ c.taffon@unicampus.it \\ 6 Unit of Psychiatry, Department of Systems Medicine, University of Rome Tor Vergata, via Montpellier 1, \\ 00133 Rome, Italy; niolu@med.uniroma2.it (C.N.); di.lorenzo@med.uniroma2.it (G.D.L.) \\ * Correspondence: v.dilazzaro@unicampus.it
}

Received: 4 May 2020; Accepted: 30 June 2020; Published: 3 July 2020

Abstract: We present a case of celiac disease (CD) diagnosis in a 75-year-old woman with a long-term history of chronic delusional jealousy and a complex neurological involvement. The case describes a very unusual clinical picture, provides some clinical clues, and highlights the importance of being aware of $\mathrm{CD}$ extraintestinal manifestations in order to get a timely diagnosis.

Keywords: celiac disease; spastic paraparesis; delusional jealousy

\section{Introduction}

Celiac disease $(C D)$ is a chronic, multi-organ autoimmune disease that affects the small bowel in genetically predisposed individuals, triggered by gluten ingestion and treated with a gluten-free $\operatorname{diet}$ (GFD) [1-3]. The prevalence of CD is rising [1], as well as the incidence of CD cases presenting with extraintestinal symptoms [4] and in adulthood [5]. Gastrointestinal manifestations of CD include diarrhea, abdominal bloating, weight loss, and nutrient malabsorption [3]. A set of extraintestinal manifestations have been associated with $\mathrm{CD}$ among which are iron-deficiency anemia, abnormalities in liver function tests, bone disease (osteopenia/osteoporosis), skin disorders, fatigue, and a wide spectrum of neurological and psychiatric disorders [1,3,5-9]. Neurologic manifestations may either precede or follow CD diagnosis and are thought to occur in about $10-20 \%$ of patients with established CD $[1,10]$. The occurrence of psychiatric symptoms in CD patients has also been known for a long time $[11,12]$ and is increasingly reported $[13,14]$. Many of the neuropsychiatric disorders associated with CD have been linked to cross-reacting immune responses or to nutritional deficiencies [6]. However, the pathophysiology of CD-associated neuropsychiatric manifestations remains largely elusive, and further systematic studies are needed to address the mechanisms of the underlying nervous system pathology. Since GFD showed to improve neuropsychiatric manifestations associated with CD in some patients $[1,7,13,15-18]$, clinicians' awareness about CD extraintestinal manifestations should be high. 


\section{Case Report}

A 75-year-old Caucasian woman came to our neurology outpatient clinic for a 10-year history of progressive walking disorder, which started at the age of 65 and slowly worsened. She complained of "stiffness" and "heaviness" in her legs, frequent falls, and painful muscle cramps. More recently, for about two years, she had noticed a slowing of her movements. She stated that for all these symptoms she had already undergone clinical and blood tests, genetic and neuroimaging assessments without receiving a diagnosis, and that she had only been treated with conventional physiotherapy.

Importantly, the patient had received a diagnosis of chronic delusional jealousy at the age of 64 , a few months after an acute episode of psychosis. For this, she had been treated with haloperidol (unknown dosage) for about one year, and then with aripiprazole ( $2.5 \mathrm{mg}$ daily) during the last nine years. Other comorbidities were high blood pressure, osteoporosis, and early insomnia.

Her past medical history was unremarkable. Her father died of a stroke, her mother of breast cancer; she had one son with great vessel transposition and no other relevant diseases in her family health history. She denied a family history of psychiatric disorders. Her medication list was aripiprazole $2.5 \mathrm{mg}$ daily, acetylsalicylic acid $100 \mathrm{mg}$ daily, ramipril $2.5 \mathrm{mg}$, amiloride-hydrochlorothiazide $2.5-25 \mathrm{mg}$ alt.d., and delorazepam $0.25 \mathrm{mg}$ daily. Furthermore, she added that she was occasionally taking natural supplements for a few years for mild bloating, not otherwise specified, and that she had recently supplemented vitamin B12. She had no allergies, and no history of alcohol, tobacco, and drug use. She had a body mass index of $24 \mathrm{~kg} / \mathrm{m}^{2}$.

At our neurological examination, we observed a complex neurological involvement. Spastic paraparesis was the prominent feature and was associated with extrapyramidal, cerebellar, and neuropathic signs. Indeed, we observed scanning speech, hypomimia, bradykinesia, intermittent right resting tremor and bilateral postural tremor, positive finger-to-nose test, spastic paraparesis with moderate distal weakness, and lower limbs hyperreflexia with a bilateral Babinski sign. She had an unsteady and wide-based gait, with reduced arm swing. She was well-oriented and scored 30/30 on the Mini-Mental State Examination (MMSE) [19]. She had no dysphagia, no nystagmus, no bladder dysfunction, and no autonomic failure.

Blood tests revealed mild normocytic anemia (hemoglobin: $11.7 \mathrm{~g} / \mathrm{dL}$ normal values (n.v.) 12-16); mild hypoproteinemia (total protein $4.90 \mathrm{~g} / \mathrm{dL}$, n.v. 6.20-8.10); mild hypoalbuminemia (3.04 g/dL; n.v. 3.20-4.20); severe folate deficiency (folic acid $0.70 \mathrm{ng} / \mathrm{mL}$; normal values (n.v.) >5.4). Vitamin B12 and serum iron were at the lower level of the normal range. Ferritin was within the normal range.

At the instrumental assessments:

- nerve conduction studies and electromyography (NCSs/EMG) documented a motor axonal polyneuropathy with signs of active denervation at the lower limbs;

- $\quad$ somatosensory and motor potentials (SEPs and MEPs) documented a complete absence of responses from the lower limbs;

- brain magnetic resonance imaging (MRI) showed non-specific periventricular gliosis (Figure 1);

- $\quad$ spinal cord MRI was normal.

Furthermore, the patient had already undergone dopamine transporter (DaT) single-photon emission tomography (SPECT) brain imaging with Ioflupane I-123 injection at the age of 73, which had detected slight striatal hypoperfusion bilaterally.

Psychiatric consultation confirmed the diagnosis of chronic delusional jealousy according to the Diagnostic and Statistical Manual of Mental Disorders (DSM)-5 criteria [20] and the adequacy of the ongoing therapy with aripiprazole $2.5 \mathrm{mg}$ daily. The patient was accessible to the psychiatric interview, lucid and well-oriented; when her husband was present, she manifested an increased level of tension with eye contact avoidance, hand-wringing, and incongruous laugh. Delusions of jealousy were still present, albeit partially criticized and associated with a lower emotional component compared to the onset, when she was not on aripiprazole. From the interview, it also emerged that, in the last years, 
the patient had developed a progressive tendency to social withdrawal. However, no significant levels of apathy, depression, and anxiety were recorded.
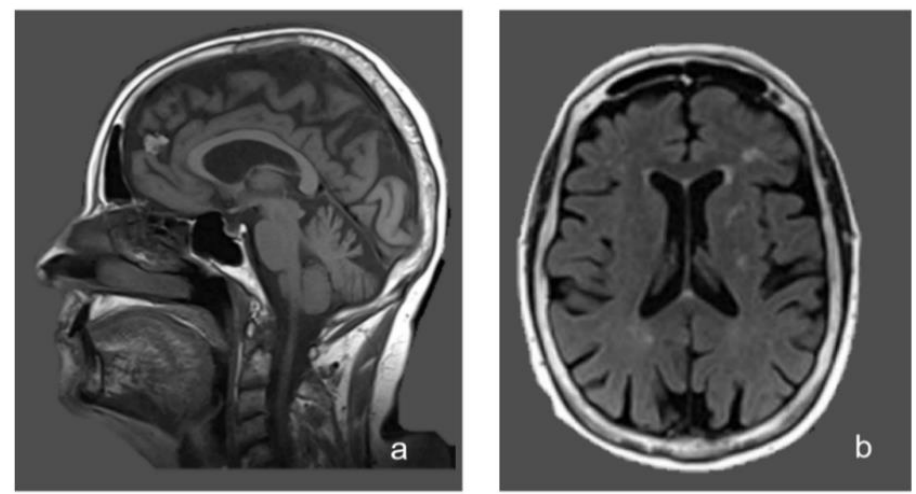

Figure 1. Sagittal (a) and axial (b) magnetic resonance imaging (MRI) Fluid-Attenuated Inversion Recovery (FLAIR) images of the patient, showing multiple areas of white matter hyperintensity and cerebellar atrophy.

Due to the finding of severe folic acid deficiency, and despite the patient reporting no clear gastrointestinal symptoms except for mild and occasional bloating, a blood screening for causes of malabsorption was performed, which ended in finding high serological levels of anti-transglutaminase (TTG) and anti-endomysial (EMA) antibodies (TTG: 36.3 AU/mL, normal values: 0.2-8; EMA: present 1:10, normal value: absent-assessed through TTG and EMA IgA ELISA kit. Anti-gliadin and vitamin E dosages not available). The diagnosis of celiac disease stage 3c (according to Marsh-Oberhuber classification) was then confirmed through a duodenal biopsy (Figure 2).
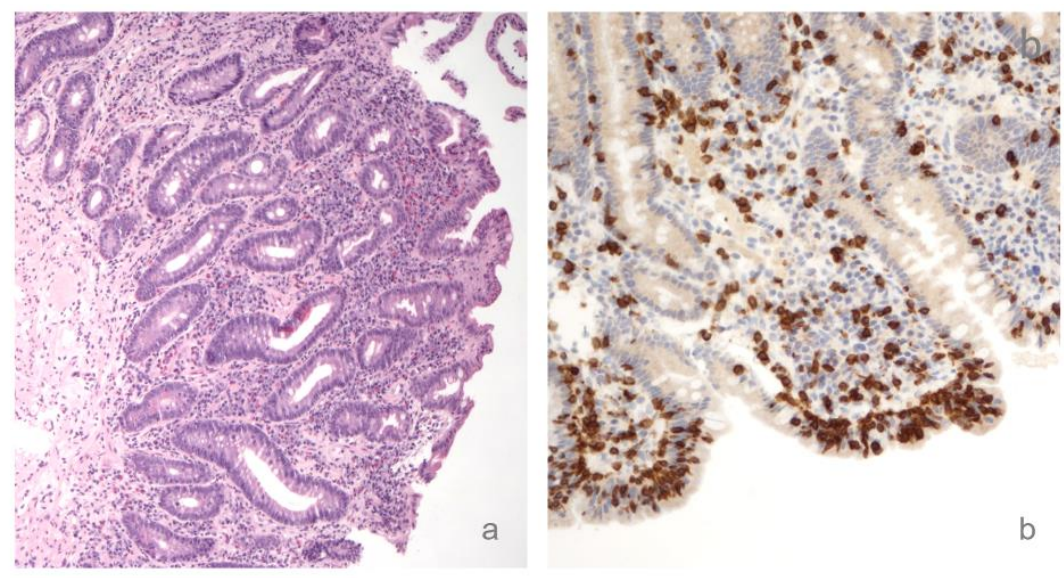

Figure 2. (a) A fragment of the patient's duodenal mucosa showing villous atrophy, glandular crypt hyperplasia, low enterocytes height, irregular brush-border and cytoplasmic vacuoles; (b) CD3 immunohistochemical staining of the duodenal mucosa showing a pathological increase of intraepithelial lymphocytes.

The patient's colonoscopy was normal, except for the distal ileum, where the mucosa showed a typical appearance of nodular lymphoid hyperplasia, without signs of acute inflammation.

GFD was started, in association with short-term folic acid replacement. At the two-month follow-up, the normalization of serum TTG and EMA antibodies and of folate levels was observed. Serum homocysteine was normal, and folic acid replacement was discontinued. During the following months, the patient noticed a subjective improvement in her gait, reduced leg stiffness and fatigability, and she had no further episodes of falling. At our objective follow-up evaluations during the following two years, her walking impairment, which had previously been progressive, did not further deteriorate. 
As an objective measure, at the nine-month follow-up, we found visible lumbar (N22) and cortical (N40) responses at the lower limb SEPs, which had previously been absent, with increased latency. MEPs remained persistently absent at lower limbs. In addition, her psychiatric condition remained stable, with no further episodes of acute psychosis. The patient's adherence to GFD was assessed during our two-year follow-up through dietary review and serial measurements of vitamins and of TTG and EMA antibodies levels [1,21]. No follow-up duodenal biopsy was performed.

A written informed consent for publication was obtained from the patient.

\section{Discussion}

We described the case of a woman who had an insidious onset of neuropsychiatric symptoms (chronic delusional jealousy and progressive walking impairment due to complex neurological involvement) at the age of 64, and was diagnosed with CD after 11 years, through serologic (TGG and EMA antibody positivity) and histologic confirmation. The detection of a severe folic acid deficiency on blood tests raised the suspicion of malabsorption and guided the clinical reasoning to the research of $C D$ as a possible unifying cause of the patient's complex neuropsychiatric picture.

CD can manifest with or be accompanied by many neurological and psychiatric disorders, both in children and in adults $[1,7,22,23]$. The first descriptions of a link between CD and neurological and psychiatric disorders date back long ago [11,12,24]. Over the years, an increasing number of case reports, case series, and population-based studies strongly supported the link between CD and neuropsychiatric disorders [9,15,25-30], although a few studies have yielded conflicting results [31-33].

Psychiatric disorders commonly observed in untreated CD patients include mood and anxiety disorders, attention deficit, autism, and schizophrenia [13]. A recent systematic review and meta-analysis confirmed that CD is associated with an increased risk of autistic spectrum disorder, attention deficit hyperactivity disorder, depression, anxiety, and eating disorders [14]. A significant positive association between $\mathrm{CD}$ and psychosis has also been recently demonstrated [34]. Neurologic diseases frequently observed in patients with CD and gluten-related disorders [2] include cerebellar ataxia, peripheral neuropathy, headache, and white matter abnormalities. Less commonly, epilepsy, myopathy, myelopathy, acute inflammatory demyelinating polyradiculoneuropathy, restless legs syndrome, dystonia, myoclonus, stiff person syndrome, cognitive impairment, pseudotumor cerebri, and brain calcifications have been described $[1,7,10,16]$. Very recently, an analysis of data from the UK Biobank, including 104 CD patients with a mean age of 63 years and 195 matched controls, further highlighted that subjects with CD have higher rates of cognitive deficit, worse mental health, and white matter changes, supporting the association between celiac disease and neurologic and psychological features [35].

The mechanisms linking CD and neuropsychiatric manifestations remain largely elusive. Current evidence suggests that neuropsychiatric manifestations of CD are immune-mediated (cross-reacting antibodies, immune-complex deposition, T cell cytotoxicity), although gluten-related toxicity, microbiome, vitamin deficiencies, and genetic association could also play a role [1,15,16,36,37]. Further, neuroinflammation triggered by autoimmune disorders and by gut microbiota alterations is being increasingly proposed as a possible link between CD and some neuropsychiatric disorders [38-41], and represents a future area of interest for research.

The association between delusional jealousy (DJ) and CD, found in our patient, has never been described before, to our best knowledge.

Delusional jealousy (also known as morbid/pathological/paranoid jealousy; Othello syndrome; delusional disorder-jealous type; conjugal paranoia) is a psychiatric disorder characterized by the firm and false belief that a spouse or lover is unfaithful [42]. DJ is classified among the subtypes of the delusional disorder in the DSM-5 [20]. DJ has been described in functional and organic psychosis, including dementia, stroke, alcoholism, traumatic brain injury (TBI) and in parkinsonian patients [43-48], but never in association with CD. In a retrospective case series of 105 patients affected by delusional jealousy, the average onset was in the 6th decade, and the condition was often associated 
with neurologic disorders [48]. The neural bases of DJ should still be clarified. Some studies highlighted the role of frontal lobes [48], and a model on the feeling of jealousy and its delusional form has been proposed, in which dopaminergic frontostriatal circuits, the ventromedial prefrontal cortex, the insula, and their related functions of reward, mentalizing, and self-related processing have been included [42]. In this case, the patient had no history of alcohol abuse, TBI, stroke, or dementia, and developed the psychiatric symptoms several years before the extrapyramidal symptoms.

The neurological picture found in our patient is also unique for its multisystemic involvement.

Indeed, the patient's walking impairment and neurological symptoms were linked to the involvement of all the following: pyramidal pathways at the spinal cord level (spastic paraparesis, bilateral Babinski sign); cerebellum (gait ataxia, scanning speech, positive finger-to-nose test); peripheral nerves (axonal motor neuropathy, distal weakness); and extrapyramidal system (hypomimia, bradykinesia, intermittent right resting tremor, reduced arm swing).

Ataxia [49], peripheral neuropathies [50], as well as brain white matter lesions [51] have been described in many cases of CD with neurological manifestations. However, other findings such as spastic paraparesis with normal spine MRI [52,53], myelopathic signs with normal spine MRI and SEPs improvement after GFD [54], parkinsonism and psychosis in CD [55], and parkinsonian symptoms improvement after GFD [56] have been described only anecdotally and not in combinations like in this case.

We performed a literature search in PubMed using the following terms: "(celiac disease OR coeliac disease) AND (psychiatric) AND (neurologic or neurological OR neuropsychiatric OR neuro-psychiatric)". We looked for case reports and/or case series and/or population-based studies, in English language, already published in the literature, which included, similarly to our case, adult patients (aged 18 or more), with biopsy-proven CD, who presented both neurological and psychiatric symptoms. Of the 68 articles found with these search keywords, and after the consultation of 24 more articles found from their references lists, only five case reports were found that responded to these inclusion characteristics (Table 1). From this search, the need for a more standardized and systematic reporting (inclusive of CD diagnosis criteria, antibody status, order of presentation of the neuropsychiatric symptoms with respect to CD diagnosis, effects of GFD) emerged.

Table 1. Case reports about adult (age $>18$ ) patients, with biopsy-proven celiac disease (CD), with neurological and psychiatric disorders.

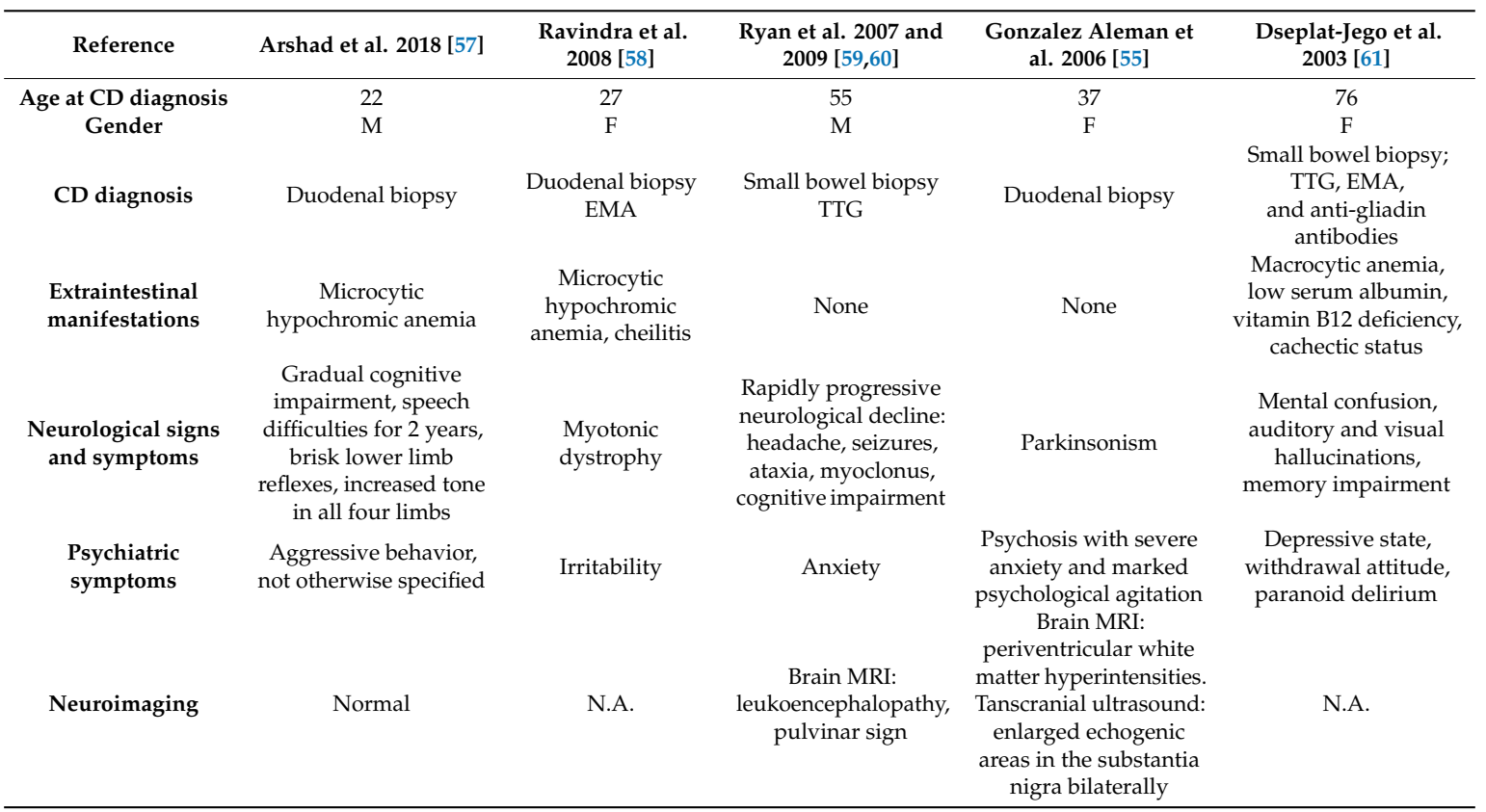


Table 1. Cont.

\begin{tabular}{|c|c|c|c|c|c|}
\hline Reference & Arshad et al. 2018 [57] & $\begin{array}{c}\text { Ravindra et al. } \\
2008[58]\end{array}$ & $\begin{array}{c}\text { Ryan et al. } 2007 \text { and } \\
2009[59,60]\end{array}$ & $\begin{array}{l}\text { Gonzalez Aleman et } \\
\text { al. } 2006 \text { [55] }\end{array}$ & $\begin{array}{c}\text { Dseplat-Jego et al. } \\
2003[61]\end{array}$ \\
\hline Treatment & GFD & $\begin{array}{l}\text { GFD, iron, calcium } \\
\text { and folic acid } \\
\text { supplements for } \\
8 \text { weeks }\end{array}$ & $\begin{array}{c}\text { Probably already on } \\
\text { GFD (CD diagnosis } \\
6 \text { months before), } \\
\text { anticonvulsants, } \\
\text { immunosuppressive } \\
\text { treatment }\end{array}$ & $\begin{array}{c}\text { Already on GFD (not } \\
\text { specified for how } \\
\text { long), clozapine }\end{array}$ & $\begin{array}{c}\text { GFD, Vit B12 } \\
\text { supplementation }\end{array}$ \\
\hline
\end{tabular}

Furthermore, we found one cross-sectional study on biopsy-proven adult (aged 18 years or more) CD patients with "neurological and/or psychiatric conditions". About $35 \%$ of the 72 patients (mean age $51+15$ ) reported a history of psychiatric problems, while the most common neurological conditions recorded were migraine $28 \%$, carpal tunnel syndrome $20 \%$, vestibular dysfunction $8 \%$, seizures $6 \%$, and myelitis 3\% [62].

The clinical picture described in our patient shares some similarities with the gluten ataxia phenotype [49] (insidious onset in adulthood, dysarthria, gait ataxia, absence of prominent gastrointestinal symptoms, cerebellar atrophy, and white matter abnormalities on MRI), frequently observed in non-celiac gluten sensitivity (NCGS) [63]. However, our patient also had spastic paraparesis, peripheral neuropathy, extrapyramidal signs, and chronic delusional jealousy. Other differential diagnoses excluded, not fully explaining the patient's clinical picture, were spinocerebellar ataxia and multiple system atrophy. Our patient had no autonomic failure, no nystagmus, no dysphagia, and no cognitive dysfunction.

The cornerstone of CD treatment is the dietary exclusion of gluten [1,5]. Several studies demonstrated that GFD could prevent neuropsychiatric manifestations of $C D$ and improve these manifestations in some patients $[1,7,13,15-18,64,65]$. Further, functional data derived from transcranial magnetic stimulation studies suggested that a long-lasting GFD could partially restore the imbalance between intracortical excitatory and inhibitory circuits in CD patients [66]. Instead, prolonged gluten exposure has been associated with poor prognosis after GFD [7,49]. All these data highlight the importance of a timely diagnosis for CD patients. After GFD, our patient had a subjective improvement, and we objectively observed the stabilization of the previously progressive neurologic impairment and the improvement of SEPs. The persistence of absent lower limb MEPs could have been influenced by the patient's motor axonal neuropathy. Regarding the patient's extrapyramidal signs, it has to be taken into account that the chronic treatment with aripiprazole, considered mandatory and thus maintained, might have contributed to the parkinsonian symptoms and to the limited gait improvement after GFD [67]. Aripiprazole is an antipsychotic drug with an uncertain mechanism of action. In animal models, it showed both, agonist or antagonist presynaptic D2 receptors activity, depending on the dopaminergic tone [68]. Among its proposed mechanisms of action, besides partial agonism on D2 dopaminergic receptors and antagonist action on $5 \mathrm{HT}_{2} \mathrm{~A}$ serotoninergic receptors, a partial agonism on $5 \mathrm{HT}_{1} \mathrm{~A}$ serotoninergic receptors has been proposed, which theoretically reduces motor side effects [69]. Furthermore, the hypothesis of drug-induced parkinsonism is improbable at the dosage assumed by the patient. In addition, the asymmetrical resting tremor and the DaT-SPECT, which suggested a defect at the presynaptic dopaminergic receptors level, are less in favor of drug-induced parkinsonism [70].

The incidence of $C D$ cases presenting in adulthood and with minimal or no gastrointestinal symptoms is rising $[4,5]$. Such a paradigm shift requires high clinician awareness. It has been estimated that $\mathrm{CD}$ diagnosis can have a median delay of 3.5 years when there are no gastrointestinal complaints (e.g., diarrhea, malabsorption, weight loss, and gassy distension) [71]. In the case described here, the advanced age of the patient, the absence of clear gastrointestinal symptoms, and the complex clinical picture made the diagnosis challenging. Bloating was described as very mild and sporadic and 
did not represent a prominent clinical clue. Instead, osteoporosis, mild anemia and hypoproteinemia can be considered systemic CD manifestations. Importantly, the severe folic acid deficiency represented a key finding and a "red flag" for possible malabsorption, which guided us towards the final diagnosis.

\section{Conclusions}

The case described highlights the importance of considering CD in the differential diagnosis of unexplained neuropsychiatric disorders, even in older adults and even in the absence of gastrointestinal symptoms.

Author Contributions: Conceptualization, V.D.L.; writing-original draft preparation, E.F.; writing-review and editing, E.F., V.D.L., F.C., F.R., L.F., M.C.; visualization, C.T., C.N., G.D.L.; supervision, V.D.L.; project administration, V.D.L. All authors have read and agreed to the published version of the manuscript.

Funding: This research received no external funding.

Conflicts of Interest: The authors declare no conflicts of interest.

\section{References}

1. Al-Toma, A.; Volta, U.; Auricchio, R.; Castillejo, G.; Sanders, D.S.; Cellier, C.; Mulder, C.J.; Lundin, K. European Society for the Study of Coeliac Disease (ESsCD) guideline for coeliac disease and other gluten-related disorders. United Eur. Gastroenterol. J. 2019, 7, 583-613. [CrossRef]

2. Ludvigsson, J.F.; Leffler, D.A.; Bai, J.C.; Biagi, F.; Fasano, A.; Green, P.H.; Hadjivassiliou, M.; Kaukinen, K.; Kelly, C.P.; Leonard, J.N.; et al. The Oslo definitions for coeliac disease and related terms. Gut 2013, 62, 43-52. [CrossRef]

3. Lindfors, K.; Ciacci, C.; Kurppa, K.; Lundin, K.; Makharia, G.K.; Mearin, M.L.; Murray, J.A.; Verdu, E.F.; Kaukinen, K. Coeliac disease. Nat. Rev. Dis. Primers 2019, 5, 3. [CrossRef]

4. Newnham, E.D. Coeliac disease in the 21st century: Paradigm shifts in the modern age. J. Gastroenterol. Hepatol. 2017, 32, 82-85. [CrossRef] [PubMed]

5. Lebwohl, B.; Sanders, D.S.; Green, P.H.R. Coeliac disease. Lancet 2018, 391, 70-81. [CrossRef]

6. White, H. Gastrointestinal Disorders and the Nervous System. Continuum 2020, 26, 577-590. [PubMed]

7. Pfeiffer, R.F. Gastroenterology and Neurology. Continuum 2017, 23, 744-761. [CrossRef] [PubMed]

8. Guandalini, S.; Assiri, A. Celiac disease: A review. JAMA Pediatr. 2014, 168, 272-278. [CrossRef] [PubMed]

9. Isikay, S.; Kocamaz, H. The Neurological Face of Celiac Disease. Arq. Gastroenterol. 2015, 52, $167-170$. [CrossRef]

10. Hadjivassiliou, M.; Duker, A.P.; Sanders, D.S. Gluten-related neurologic dysfunction. Handb. Clin. Neurol. 2014, 120, 607-619.

11. Hallert, C.; Derefeldt, T. Psychic disturbances in adult coeliac disease. I. Clinical observations. Scand. J. Gastroenterol. 1982, 17, 17-19. [CrossRef] [PubMed]

12. Walsh, D. Coeliac disease and schizophrenia. Br. Med. J. 1973, 2, 242. [CrossRef] [PubMed]

13. Campagna, G.; Pesce, M.; Tatangelo, R.; Rizzuto, A.; La Fratta, I.; Grilli, A. The progression of coeliac disease: Its neurological and psychiatric implications. Nutr. Res. Rev. 2017, 30, 25-35. [CrossRef]

14. Clappison, E.; Hadjivassiliou, M.; Zis, P. Psychiatric Manifestations of Coeliac Disease, a Systematic Review and Meta-Analysis. Nutrients 2020, 12, 142. [CrossRef]

15. Tengah, D.P.; Wills, A.J.; Holmes, G.K. Neurological complications of coeliac disease. Postgrad. Med. J. 2002, 78, 393-398. [CrossRef]

16. Hadjivassiliou, M.; Rao, D.G.; Grìnewald, R.A.; Aeschlimann, D.P.; Sarrigiannis, P.G.; Hoggard, N.; Aeschlimann, P.; Mooney, P.D.; Sanders, D.S. Neurological Dysfunction in Coeliac Disease and Non-Coeliac Gluten Sensitivity. Am. J. Gastroenterol. 2016, 111, 561-567. [CrossRef] [PubMed]

17. Cicarelli, G.; Della Rocca, G.; Amboni, M.; Ciacci, C.; Mazzacca, G.; Filla, A.; Barone, P. Clinical and neurological abnormalities in adult celiac disease. Neurol. Sci. 2003, 24, 311-317. [CrossRef] [PubMed]

18. Van Hees, N.J.M.; van der Does, W.; Giltay, E.J. Coeliac disease, diet adherence and depressive symptoms. J. Psychosom. Res. 2013, 74, 155-160. [CrossRef]

19. Folstein, F.M.; Folstein, S.E.; McHugh, P.R. "Mini-mental state". A practical method for grading the cognitive state of patients for the clinician. J. Psychiatr. Res. 1975, 12, 189-198. 
20. American Psychiatric Association. Diagnostic and Statistical Manual of Mental Disorders, 5th ed.; American Psychiatric Association: Washington, DC, USA, 2013.

21. Nachman, F.; Sugai, E.; Vázquez, H.; González, A.; Andrenacci, P.; Niveloni, S.; Mazure, R.; Smecuol, E.; Moreno, M.L.; Hwang, H.J.; et al. Serological tests for celiac disease as indicators of long-term compliance with the gluten-free diet. Eur. J. Gastroenterol. Hepatol. 2011, 23, 473-480. [CrossRef] [PubMed]

22. Bushara, K.O. Neurologic presentation of celiac disease. Gastroenterology 2005, 128, S92-S97. [CrossRef] [PubMed]

23. Hankey, L.G.; Holmes, G.K. Coeliac disease in the elderly. Gut 1994, 35, 65-67. [CrossRef] [PubMed]

24. Cooke, T.W.; Smith, W.T. Neurological disorders associated with adult coeliac disease. Brain 1966, 89, 683-722. [CrossRef] [PubMed]

25. Trovato, C.M.; Raucci, U.; Valitutti, F.; Montuori, M.; Villa, M.P.; Cucchiara, S.; Parisi, P. Neuropsychiatric manifestations in celiac disease. Epilepsy Behav. 2019, 99, 106393. [CrossRef] [PubMed]

26. Cossu, G.; Carta, M.G.; Contu, F.; Mela, Q.; Demelia, L.; Elli, L.; Dell'Osso, B. Coeliac disease and psychiatric comorbidity: Epidemiology, pathophysiological mechanisms, quality-of-life, and gluten-free diet effects. Int. Rev. Psychiatry 2017, 29, 489-503. [CrossRef]

27. Addolorato, G.; Mirijello, A.; D’Angelo, C.; Leggio, L.; Ferrulli, A.; Abenavoli, L.; Vonghia, L.; Cardone, S.; Leso, V.; Cossari, A.; et al. State and trait anxiety and depression in patients affected by gastrointestinal diseases: Psychometric evaluation of 1641 patients referred to an internal medicine outpatient setting. Int. J. Clin. Pract. 2008, 62, 1063-1069. [CrossRef]

28. Addolorato, G.; Leggio, L.; D’Angelo, C.; Mirijello, A.; Ferrulli, A.; Cardone, S.; Vonghia, L.; Abenavoli, L.; Leso, V.; Nesci, A.; et al. Affective and psychiatric disorders in celiac disease. Dig. Dis. 2008, 26, 140-148. [CrossRef]

29. Luostarinen, L.; Pirttila, T.; Collin, P. Coeliac disease presenting with neurological disorders. Eur. Neurol. 1999, 42, 132-135. [CrossRef]

30. Hadjivassiliou, M.; Chattopadhyay, A.K.; Davies-Jones, G.A.; Gibson, A.; Grunewald, R.A.; Lobo, A.J. Neuromuscular disorder as a presenting feature of coeliac disease. J. Neurol. Neurosurg. Psychiatry 1997, 63, 770-775. [CrossRef]

31. Ludvigsson, J.F.; Reichenberg, A.; Hultman, C.M.; Murray, J.A. A nationwide study of the association between celiac disease and the risk of autistic spectrum disorders. JAMA Psychiatry 2013, 70, 1224-1230. [CrossRef]

32. Pavone, L.; Fiumara, A.; Bottaro, G.; Mazzone, D.; Coleman, M. Autism and celiac disease: Failure to validate the hypothesis that a link might exist. Biol. Psychiatry 1997, 42, 72-75. [CrossRef]

33. Smith, F.D.; Gerdes, L.U. Meta-analysis on anxiety and depression in adult celiac disease. Acta Psychiatr. Scand. 2012, 125, 189-193. [CrossRef] [PubMed]

34. Cullen, A.E.; Holmes, S.; Pollak, T.A.; Blackman, G.; Joyce, D.W.; Kempton, M.J.; Murray, R.M.; McGuire, P.; Mondelli, V. Associations Between Non-neurological Autoimmune Disorders and Psychosis: A Meta-analysis. Biol. Psychiatry 2019, 85, 35-48. [CrossRef] [PubMed]

35. Croall, I.D.; Sanders, D.S.; Hadjivassiliou, M.; Hoggard, N. Cognitive Deficit and White Matter Changes in Persons With Celiac Disease: A Population-Based Study. Gastroenterology 2020, 158, 2112-2122. [CrossRef] [PubMed]

36. Hadjivassiliou, M.; Sanders, D.S.; Grunewald, R.A.; Woodroofe, N.; Boscolo, S.; Aeschlimann, D. Gluten sensitivity: From gut to brain. Lancet Neurol. 2010, 9, 318-330. [CrossRef]

37. Tylee, D.S.; Sun, J.; Hess, J.L.; Tahir, M.A.; Sharma, E.; Malik, R.; Worrall, B.B.; Levine, A.J.; Martinson, J.J.; Nejentsev, S. Genetic correlations among psychiatric and immune-related phenotypes based on genome-wide association data. Am. J. Med. Genet. B Neuropsychiatr. Genet. 2018, 177, 641-657. [CrossRef]

38. Severance, G.E.; Yolken, R.H.; Eaton, W.W. Autoimmune diseases, gastrointestinal disorders and the microbiome in schizophrenia: More than a gut feeling. Schizophr. Res. 2016, 176, 23-35. [CrossRef]

39. Galland, L. The gut microbiome and the brain. J. Med. Food 2014, 17, 1261-1272. [CrossRef]

40. Camara-Lemarroy, C.R.; Rodriguez-Gutierrez, R.; Monreal-Robles, R.; Marfil-Rivera, A. Gastrointestinal disorders associated with migraine: A comprehensive review. World J. Gastroenterol. 2016, 22, 8149-8160. [CrossRef]

41. Yelland, G.W. Gluten-induced cognitive impairment ("brain fog") in coeliac disease. J. Gastroenterol. Hepatol. 2017, 32, 90-93. [CrossRef] 
42. Marazziti, D.; Poletti, M.; Dell'Osso, L.; Baroni, S.; Bonuccelli, U. Prefrontal cortex, dopamine, and jealousy endophenotype. CNS Spectr. 2013, 18, 6-14. [CrossRef] [PubMed]

43. Batinic, B.; Duisin, D.; Barisic, J. xObsessive versus delusional jealousy. Psychiatr. Danub. 2013, 25, 334-339.

44. Seeman, M.V. Pathological Jealousy: An Interactive Condition. Psychiatry 2016, 79, 379-388. [CrossRef] [PubMed]

45. Cannas, A.; Solla, P.; Floris, G.; Tacconi, P.; Marrosu, F.; Marrosu, M.G. Othello syndrome in Parkinson disease patients without dementia. Neurologist 2009, 15, 34-36. [CrossRef]

46. Braun, M.C.; Suffren, S. A general neuropsychological model of delusion. Cogn. Neuropsychiatry 2011, 16, 1-39. [CrossRef]

47. Ortigue, S.; Bianchi-Demicheli, F. Intention, false beliefs, and delusional jealousy: Insights into the right hemisphere from neurological patients and neuroimaging studies. Med. Sci. Monit. 2011, 17, RA1-RA11.

48. Graff-Radford, J.; Whitwell, J.L.; Geda, Y.E.; Josephs, K.A. Clinical and imaging features of Othello's syndrome. Eur. J. Neurol. 2012, 19, 38-46. [CrossRef]

49. Hadjivassiliou, M.; Sanders, D.D.; Aeschlimann, D.P. Gluten-related disorders: Gluten ataxia. Dig. Dis. 2015, 33, 264-268. [CrossRef]

50. Hadjivassiliou, M.; Grünewald, R.A.; Kandler, R.H.; Chattopadhyay, A.K.; Jarratt, J.A.; Sanders, D.S.; Sharrack, B.; Wharton, S.B.; Davies-Jones, G.A. Neuropathy associated with gluten sensitivity. J. Neurol. Neurosurg. Psychiatry 2006, 77, 1262-1266. [CrossRef]

51. Kieslich, M.; Errazuriz, G.; Posselt, H.G.; Moeller-Hartmann, W.; Zanella, F.; Boehles, H. Brain white-matter lesions in celiac disease: A prospective study of 75 diet-treated patients. Pediatrics 2001, 108, E21. [CrossRef] [PubMed]

52. Makhlouf, S.; Msselemeni, M.; Derbali, H.; Mansour, M.; Zaouali, J.; Mrissa, R. Spastic paraparesis revealing celiac disease. Acta Gastroenterol. Belg. 2018, 81, 107-108. [PubMed]

53. Frih-Ayed, M.; Boughammoura-Bouatay, A.; Fitouri, F.; Chebel, S. Coeliac disease an spastic paraplegia. Rev. Neurol. 2006, 162, 648-650. [CrossRef]

54. Di Lazzaro, V.; Pilato, F.; Batocchi, A.P.; Restuccia, D.; Cammarota, G.; Profice, P. Tired legs-a gut diagnosis. Lancet 2010, 376, 1798. [CrossRef]

55. Gonzalez Aleman, G.; Florenzano, N.; Padilla, E.; Bourdieu, M.; Guerrero, G.; Calvó, M.; Alberio, G.; Strejilevich, S.; de Erausquin, G.A. A 37-year-old woman with celiac disease, recurrent psychosis, and Parkinsonism. Mov. Disord. 2006, 21, 729-731. [CrossRef]

56. Di Lazzaro, V.; Capone, F.; Cammarota, G.; Di Giuda, D.; Ranieri, F. Dramatic improvement of parkinsonian symptoms after gluten-free diet introduction in a patient with silent celiac disease. J. Neurol. 2014, 261, 443-445. [CrossRef]

57. Arshad, I.; Javeed, A.; Ullah, U. Patient with Gluten Encephalopathy Presenting with Neuropsychiatric Symptoms. Am. J. Med. 2018, 131, e49-e50. [CrossRef]

58. Ravindra, B.S.; Desai, N.; Deviprasad, S.; Bhede, V.; Ravat, S.; Sawant, P. Myotonic dystrophy in a patient of celiac disease: A new association? Trop. Gastroenterol. 2008, 29, 114-115.

59. Ryan, A.M.; Ryan, J.; Wan-Ahmed, M.; Hardiman, O.; Farrell, M.A.; McNamara, B.; Sweeney, B.J. Vacuolar leucoencephalopathy and pulvinar sign in association with coeliac disease. BMJ Case Rep. 2009, 2009, bcr08.2008.0650.

60. Ryan, A.M.; Ryan, J.; Wan-Ahmed, M.; Hardiman, O.; Farrell, M.A.; McNamara, B.; Sweeney, B.J. Vacuolar leucoencephalopathy and pulvinar sign in association with coeliac disease. J. Neurol. Neurosurg. Psychiatry 2007, 78, 98-99. [CrossRef]

61. Dseplat-Jego, S.; Bernard, D.; Bagneres, D.; Frances, Y. Neuropsychiatric symptoms in the elderly: Let us not forget celiac disease. J. Am. Geriatr. Soc. 2003, 51, 884-885. [CrossRef]

62. Burk, K.; Farecki, M.L.; Lamprecht, G.; Roth, G.; Decker, P.; Weller, M.; Rammensee, H.G.; Oertel, W. Neurological symptoms in patients with biopsy proven celiac disease. Mov. Disord. 2009, 24, 2358-2362. [CrossRef] [PubMed]

63. Rodrigo, L.; Hernández-Lahoz, C.; Lauret, E.; Rodriguez-Peláez, M.; Soucek, M.; Ciccocioppo, R.; Kruzliak, P. Gluten ataxia is better classified as non-celiac gluten sensitivity than as celiac disease: A comparative clinical study. Immunol. Res. 2016, 64, 558-564. [CrossRef] [PubMed]

64. Kalaydjian, A.E.; Eaton, W.; Cascella, N.; Fasano, A. The gluten connection: The association between schizophrenia and celiac disease. Acta Psychiatr. Scand. 2006, 113, 82-90. [CrossRef] [PubMed] 
65. Addolorato, G.; Capristo, E.; Ghittoni, G.; Valeri, C.; Mascianà, R.; Ancona, C.; Gasbarrini, G. Anxiety but not depression decreases in coeliac patients after one-year gluten-free diet: A longitudinal study. Scand. J. Gastroenterol. 2001, 36, 502-506. [CrossRef]

66. Pennisi, M.; Lanza, G.; Cantone, M.; Ricceri, R.; Ferri, R.; D’Agate, C.C.; Pennisi, G.; Di Lazzaro, V.; Bella, R. Cortical involvement in celiac disease before and after long-term gluten-free diet: A Transcranial Magnetic Stimulation study. PLOS ONE 2017, 12, e0177560. [CrossRef]

67. Selfani, K.; Soland, V.L.; Chouinard, S.; Huot, P. Movement Disorders Induced by the “Atypical” Antipsychotic Aripiprazole. Neurologist 2017, 22, 24-28. [CrossRef]

68. Ma, G.F.; Raivio, N.; Sabria, J.; Ortiz, J. Agonist and antagonist effects of aripiprazole on D(2)-like receptors controlling rat brain dopamine synthesis depend on the dopaminergic tone. Int. J. Neuropsychopharmacol. 2014, 18, pyu046. [CrossRef]

69. Stahl, S.M. Stahl's Essential Psychopharmacology: Neuroscientific Basis and Practical Application, 4th ed.; Cambridge University Press: Cambridge, UK, 2013.

70. Shin, W.H.; Chung, S.J. Drug-induced parkinsonism. J. Clin. Neurol. 2012, 8, 15-21. [CrossRef]

71. Paez, M.A.; Gramelspacher, A.M.; Sinacore, J.; Winterfield, L.; Venu, M. Delay in Diagnosis of Celiac Disease in Patients Without Gastrointestinal Complaints. Am. J. Med. 2017, 130, 1318-1323. [CrossRef]

(C) 2020 by the authors. Licensee MDPI, Basel, Switzerland. This article is an open access article distributed under the terms and conditions of the Creative Commons Attribution (CC BY) license (http://creativecommons.org/licenses/by/4.0/). 